\title{
A Framework of the New-Typed Equipment Maintenance Support Information Management System
}

\author{
Weijie Liang ${ }^{1, ~ a ~, ~ J i n n a ~ J i a ~}{ }^{2, b}$, Guangyao Lian ${ }^{3, c}$, and Xingxin $\mathrm{Li}^{4, \mathrm{~d}}$ \\ ${ }^{1,3}$ Institute of Mechanical Engineering, Mechanical Engineering College , Beixin Street, \\ Shijiazhuang City, Hebei Province, China, 050000. \\ ${ }^{2}$ College of Information Technology and Culture Management, Hebei Institute of Communications, \\ Jingan Street of Xinhua Zone, Shijiazhuang City, Hebei Province, China, 050000. \\ ${ }^{4}$ Maintenance Engineering Institute of Equipment Demand and Management, Mechanical \\ Engineering College, West Heping Road, Shijiazhuang City, Hebei Province, China, 050003.

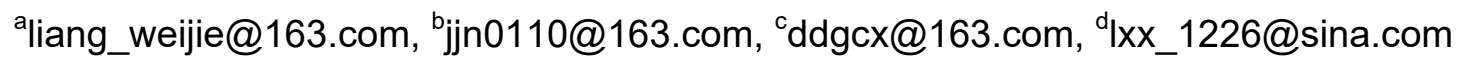

Keywords: New-typed equipment, maintenance support, software system, framework design.

\begin{abstract}
This paper analyzes the disadvantages of the new-typed equipment maintenance support information generated in different stages, different sub-sector's management, and the lack of the unified standards, to solve which, we proposes a new equipment information management system concept, which is with a set of functions of support information project management, equipment structure management, equipment property management, and have equipment function management, fault and maintenance task analysis functions, discusses the system business-rules, functions, interfaces and other requirements, builds the related information models, analysis of the basic processes used in its operation., constructs the architecture of the software system, and further analyzes the secondary extraction and operation patterns of the maintenance support information based on the system, which provide technical support to integrate the equipment maintenance information among the equipment research and development departments, the equipment operation departments and the maintenance support departments.
\end{abstract}

\section{Introduction}

For a long time, it is a very difficult problem to obtain the information of equipment maintenance support form the new equipment research and development processes, which is specific performed in three aspects:

Firstly, the information acquisition cycle is too long, the extractions of the equipment support related information from a large number of technical data is often after the equipment finalization, after then the technical manual or other types of data began to create or author, which often span a long time, and the efficiency is not obvious.

Secondly, the demand information requirement is not clear, the equipment research and development information is massive, in which the equipment support data required is just one part, but the equipment operation department did not know what information they can get form the equipment research and development department, simultaneously, the equipment research and development department also did not have the real information requirements of the equipment operation department.

Thirdly, it is difficult to exchange information, mainly in two aspects: (1) Many electronic technology data format is not uniform, resulting in a lot of information cannot be directly interactive; (2) The interactive electronic technical manual (IETM) as the representative of the electronic publication standards are inconsistent, resulting in the difficulty of information interaction, especially in recent years a number of research and development departments or units have been introduced to the IETM for data management. But these IETM standards are based on the European and American standards, and the actual situation in China is more or less different, which also cannot fully meet the 
operation, maintenance and training support requirement of new equipment, sometimes not only cannot exchange information, but also caused a huge waste of information resources.

In the field of new equipment maintenance support, there is still a lack of perfect specifications to unify the work of research and development departments, equipment operation departments, maintenance departments, which has led to the technical aspects of the gap, for example, there are a series of strict analysis and testing in the equipment development and production process of its work principle, composition structure, technical indicators, etc., and these data are very important in the process of equipment maintenance and support work. At the same time in the process of equipment operation, maintenance, a lot of experience data can also be used as a reference for equipment improvement. So a perfect equipment integrated information service platform for scientific research, operation, support and other fields of work are of certain significance. Therefore, it is necessary to carry out the research and development of new equipment maintenance support information management system, this paper focuses on the software architecture of the system.

\section{Requirements of the equipment maintenance information management system}

Through the analysis of the maintenance related work in the whole life-cycle of the equipment, the equipment maintenance information management system should mainly cover the following functions.

Business requirements. Mainly on the technical performance of the equipment, maintenance work analysis and management, as well as the analysis of data preview and output.

Functional requirements. Mainly includes:

Project management. New project, for a certain equipment can establish perfect data information model to meet the needs of various analysis and statistics; Project backup, the development of the project to carry out real-time external storage to prevent information loss caused by misoperation in the development process; Project recovery, the recovery of an equipment project to the early development version, to facilitate real-time recovery of the original data, and maintain a number of versions of the model.

Equipment structure management. Create equipment structure according to the physical structure information using systems, subsystems, components, parts, such as different levels of development; In order to improve the efficiency of the system can meet the equipment node copy, paste, etc., such as a reusable system copy, added to the application to the system, and can realize the merger of different project tree.

Equipment attribute management. Add the comprehensive properties information to the in-develop equipment structure to give a comprehensive description of the characteristics of the equipment.

Equipment function, failure and maintenance task analysis. We can analysis the layer in-develop equipment by Failure Mode Effective Analysis (FMEA) and Reliability Centered Maintenance (RCM) analysis, formulate corrective maintenance and preventive maintenance strategy, analyze maintenance tasks, statistic the required variety of maintenance resource.

Maintenance support information preview. Can preview the FMEA, RCM and other analysis of the results, while maintenance task allocation table, maintenance resource statistics and other information can be visualized.

Publication information extraction and second authoring. According to the structure of the corresponding directory of publications data node query and read, to form the complete structure of the publication information.

Maintenance support data output. In the basic of the early development data and information, combined with the publication directory structure, out put the second edited data and information, and then save it as a common office document.

Interface requirements. Mainly includes:

File output. Can achieve excel, word and other formats of the output file. 
Import external data. The database information analysis after the introduction, the data structure information in different formats to make different implementation strategies.

\section{Information model of equipment maintenance support information management system}

Through the equipment life-cycle maintenance work analysis, the equipment maintenance information structure model is shown in figure 1 . The composition relations between the various parts can be described in this way: departments managed the appropriate personnel, spares, tools, etc., provide the corresponding working environment, and formulate rules for the corresponding maintenance activities; the carrier of equipment information is the components of a equipment; part maintenance activities rely mainly on department, personnel, environment, spare, etc.. In order to implement the effective maintenance activities must have the corresponding environmental and abide by the relevant rules. The relationship is shown in figure 2 .

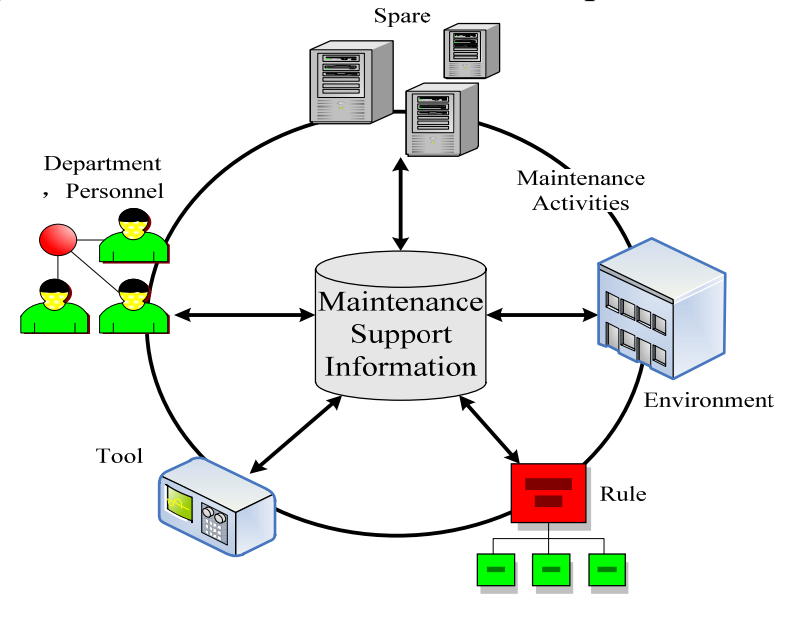

Fig. 1 the composition of maintenance support information

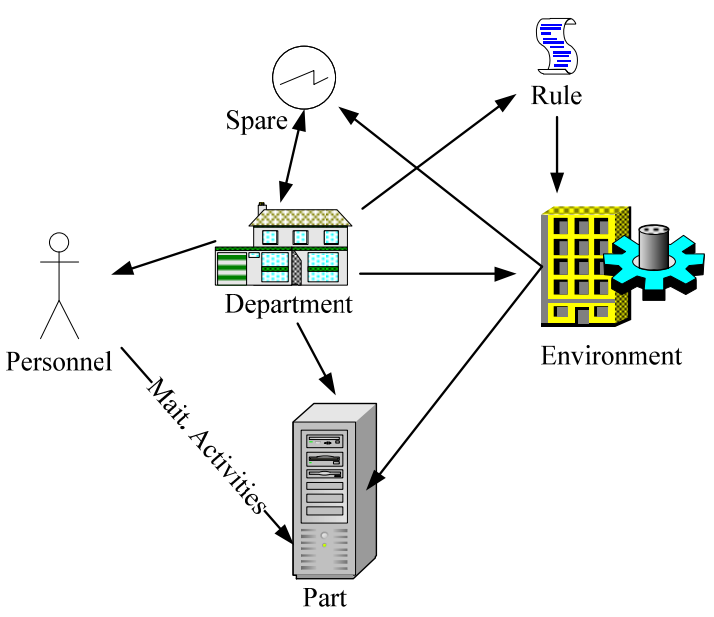

Fig. 2 the relation between information units

Department are responsible for the development, organization and implementation of maintenance activities, preparation of various maintenance equipment, application maintenance and support for maintenance of electronic publications.

Parts are the component of the equipment, which is part of the maintenance support spart catalog and maintenance task allocation chart.

Parts are treated as the maintenance spares in the maintenance support information, which is provided by the equipment research and development departments.

Personnel in the maintenance information mainly includes five types: operation personnel, maintenance personnel (include personnel in charge of measurement examination and determination), spare supply personnel, supervision \& management personnel, and teaching and training personnel. The personnel information is provided by the equipment research \& development departments and the army maintenance support scientific research institutions.

Environment mainly includes the operation environment, the place environment and the repair environment. Environmental information is provided by the equipment research \& development departments and the operation departments.

Spares mainly includ the tools, parts, accessories, instrument (device), oil, material, etc.. The spare information is mainly provided by the equipment research \& development departments.

Rules mainly refers to various types of maintenance activities (such as inspection and maintenance, fault repair, measurement and verification, battlefield repair, etc.) planning, organization, procedures, etc.. Rules are provided by the equipment research \& development departments and the operation $\&$ maintenance departments.

Maintenance activities are the reflected focus of the information listed above, and also the main content of the completion of maintenance support work. 
There we choose the XML as the information description language, and establish the model of maintenance support information. Through the previous analysis, from the information point of view, the dependence of these models, as shown in figure 3.

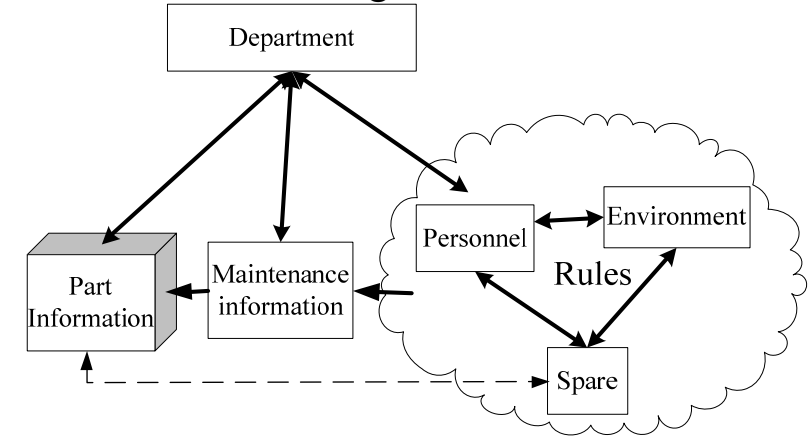

Fig. 3 the dependency relations between basic information

Basic process of the equipment maintenance supply information management system

The main process of the system is shown in Figure 4.

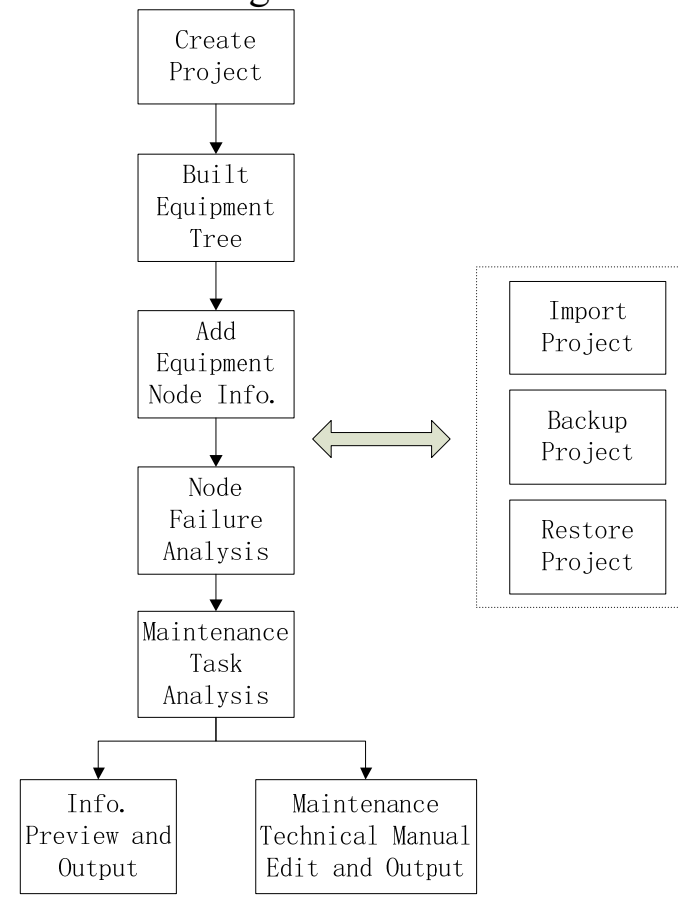

Fig. 4 the main process of the software system

\section{System architecture of the equipment maintenance support information management}

The system can integrate the technical data and the experience data in the processes of the equipment research, development, operation, maintenance, etc., build the comprehensive, analyzable digital equipment model through the information input and the equipment structure tree. At the same time, the corresponding data association storage function can facilitate the work of the subsequent analysis to assist operation personnel to complete the functional analysis, fault location and fault isolation and recovery, and according to the specific standards to preview and output the information, generate publications that meet the relevant standards' requirements.

The overall design ideas of the software is shown in Figure 5. 


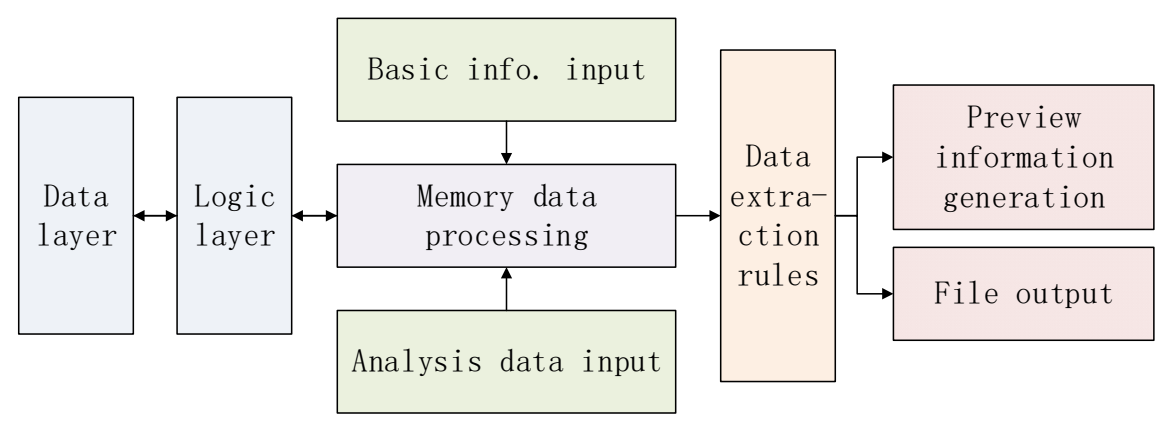

Fig. 5 the software architecture sketch map

Logic layer and data layer is mainly used for the storage and management of data for all equipment information, manage the basic equipment information, fault analysis data, maintenance support data, etc., through specific database structure.

Memory data processing module is used to store the real-time editing data and the basic system information, in the initialization process it can complete the loading of the in-memory data, which can increase in data query and output efficiency.

Basic information input and analysis data input is the main input interface of system data, which can complete the input of the equipment structure, basic information, FMEA information, RCM data, maintenance work analysis data, publications secondary data-editing and other types of analysis.

After the completion of the data input and process, we can according to the specific extraction rules to extract the corresponding data, the final output, the output form for the page display and file output, and others categories.

\section{Extraction method of the equipment maintenance support information management system information}

The data extraction process is mainly used to aid the information preview and file output activities, to obtain the related data form the database query, then to be displayed in specific view. The main function is divided into three steps:

Data query and extraction. According to the specific requirements, the corresponding attribute information, maintenance information, maintenance resource information are extracted.

Preview interface generation (preview style dynamic creation and data display). Preview the required information in the process, collate the data by the specific forms to understand and view easily.

Data export (word, Excel, etc.). Output through the file export function to see the contents of the preview, save as a separate edit file.

According to the maintenance and support technical information written specifications and content organization structures, the system need to automatically generate the corresponding directory. For example, in repair tutorial, maintenance manuals, it need to view the troubleshooting and maintenance task information and related resources. The publication generation interface will according to these content to generate the corresponding directory and in the directory nodes associated with specific information in the data, to facilitate information secondary edit and the uniform output. The system according to the publication standards, according to the equipment structure tree to establish a directory structure. In the directory structure building process, the corresponding data information from the database were extracted and the and the corresponding node associated, the user can query, modify, and delete any date below any node, and can save it to a separate database table, which ensure that the publication data will not impact on the equipment structure itself and the underlying data in the data structure. 


\section{Summary}

Through new equipment maintenance support information management system analysis and design research and development, the data of each new equipment's life-cycle phase can be management in a standardized way, which plays a supplementary role in the work of equipment research and production departments, operation departments, and maintenance departments, etc., simultaneously, it plays a certain role in promoting the new equipment development, equipment cost reduction, and the support efficiency improvement, it can also promote the supportability as soon as possible after the equipment research and development finalization.

\section{References}

[1] Military standard of the People's Republic of China, GJB std. 368B, 2009.

[2] Military standard of the People's Republic of China, GJB std. 3872, 1999. 